\title{
Beclin-1 suppresses gastric cancer progression by promoting apoptosis and reducing cell migration
}

\author{
YANFENG WANG ${ }^{1}$, JIANYING XIE ${ }^{2}$, HAO WANG $^{3}$, HAIXIA HUANG ${ }^{2}$ and PING XIE ${ }^{2}$ \\ ${ }^{1}$ Department of Pathology, Heilongjiang Province Land Reclamation Headquarter General Hospital, \\ Harbin, Heilongiang 150088; ${ }^{2}$ Department of Pathology, King Medical Diagnostics Center, Shanghai 201321; \\ ${ }^{3}$ Department of Physical Diagnostics, Heilongjiang Province Land Reclamation Headquarter General Hospital, \\ Harbin, Heilongjiang 150088, P.R. China
}

Received June 28, 2016; Accepted August 15, 2017

DOI: $10.3892 / \mathrm{ol} .2017 .7046$

\begin{abstract}
To investigate Beclin-1 expression in gastric cancer and its clinical relevance, 60 samples were collected from patients with gastric carcinoma, which were subjected to immunohistochemical staining and analysis. Associations of Beclin-1 expression with the clinical parameters of the patients, including tumor size, histological differentiation and metastatic status, were examined by statistical analysis. The results demonstrated that Beclin-1 expression in gastric carcinoma tissue was significantly associated with the tumor, node, metastasis stage and tumor invasion status. Further experiments indicated that Beclin-1 overexpression promoted MKN-45 gastric cancer cell apoptosis and inhibited their migration. These data suggested that Beclin-1 was a suppressor of tumorigenesis in gastric cancer and a potential therapeutic target for patients with gastric cancer.
\end{abstract}

\section{Introduction}

Autophagy serves an important role in maintaining cell metabolism and homeostasis (1). Autophagy is a process of endogenous substrate digestion in cells; autophagosomes are formed, and mature proteins or damaged organelles in the cytoplasm are encased by lysosomes, in which lysosomal proteases degrade them.

During tumorigenesis and tumor progression, autophagy exerts its role as a tumor suppressor by removing abnormally folded proteins and dysfunctional organelles such as mitochondria, inhibiting cell stress responses (2). However, in instances of nutritional deficiencies and hypoxia, autophagy supports tumor cell survival, which promotes cell proliferation and

Correspondence to: Dr Ping Xie, Department of Pathology, King Medical Diagnostics Center, 3377 Kangxin Road, Pudong, Shanghai 201321, P.R. China

E-mail: xieping76@hotmail.com

Key words: Beclin-1, gastric cancer, tumorigenesis, apoptosis, migration suppresses cell death (3). Compromised autophagy promotes chromosomal instability, including increased DNA damage, gene amplification and aneuploidy (4).

As a key autophagy regulator associated with apoptosis and differentiation, the autophagy-associated protein Beclin-1 has been demonstrated to be involved in many types of cancer, including ovarian carcinoma (5), hepatocellular carcinoma (6), melanoma (7), rectal cancer (8) and tongue squamous cell carcinoma (9). It has been suggested that the endogenous Beclin-1 protein expression is frequently low in human breast epithelial carcinoma cell lines and tissues, whereas it is expressed ubiquitously at high levels in normal breast epithelia (10). Concomitantly, the autophagy-promoting activity in the MCF7 breast cancer cell line following transfection with Beclin-1 was observed to inhibit MCF7 proliferation, clonogenicity and tumorigenesis (10). A previous in vivo study demonstrated that mice with inactivated or deleted Beclin-1 were susceptible to tumors including lymphoma, lung cancer and liver cancer $(11,12)$.

Beclin-1 modulates cancer initiation and progression by affecting a wide range of pathological events, including extracellular matrix degradation, epithelial-to-mesenchymal transition, tumor angiogenesis and alterations to the tumor microenvironment (13). However, the effect of Beclin-1 in cancer development is complex, as a number of reports have indicated the pro-neoplastic and anti-neoplastic functions for Beclin-1, as reviewed by Ozpolat and Benbrook (14). The present study aimed to address Beclin-1 expression and its clinical significance in gastric cancer, a type of cancer with one of the highest incidence rates worldwide, and to explore its primary potential mechanism.

\section{Materials and methods}

Clinical specimens and patient data. A total of 60 specimens of gastric carcinoma tumors and para-carcinoma tissues were sampled from patients during resection in Heilongjiang Province Land Reclamation Headquarter General Hospital (Harbin, China) between January 2014 and February 2016. The clinicopathological data of all cases were reviewed, including patient age, sex, tumor size, differentiation status, tumor node metastasis (TNM) stage, lymph node 
metastasis and invasion status (Table I) (15). No patients had received preoperative chemotherapy and radiotherapy, and those who succumbed to other diseases or accidents were excluded from the study. All specimens were fixed in $10 \%$ neutral formaldehyde at room temperature for 24-48 h, and embedded in paraffin at $65^{\circ} \mathrm{C}$ and cut into $5-\mu \mathrm{m}$ sections All specimens were subjected to hematoxylin staining for $5 \mathrm{~min}$ and eosin staining for $1 \mathrm{~min}$ at room temperature and diagnosed as gastric carcinoma by two pathologists. Informed consent was obtained from all patients or their relatives. The experimental protocol was approved by the Ethics Committee of the King Medical Diagnostics Center (Shanghai, China).

Cell culture and transfection. MKN-45, MKN-28, and SGC-7901 gastric cancer cell lines (Cancer Cell Bank, Chinese Academy of Medical Sciences, Beijing, China) were cultured in Dulbecco's modified Eagle's medium (DMEM; PAN Biotech GmbH, Aidenbach, Germany) supplemented with $10 \%$ fetal bovine serum (FBS; Hyclone; GE Healthcare Life Sciences, Logan, UT, USA) at $37^{\circ} \mathrm{C}$ with $5 \% \mathrm{CO}_{2}$. Western blot analysis determined that Beclin-1 expression was relatively low in the MKN-45 cell line (data not shown), thus the MKN-45 cell line was selected for all follow-up overexpression experiments.

The Beclin-1 sequence was cloned into a PCDNA3.0 plasmid (Invitrogen; Thermo Fisher Scientific, Inc., Waltham, MA, USA). For transfection, the cells were seeded at a density of $1 \times 10^{5} /$ well in a 24 -well plate and grown to $>50-70 \%$ confluency. A total of $1 \mu 1$ Lipofectamine $2000^{\circledR}$ (Invitrogen; Thermo Fisher Scientific, Inc.) was added to $50 \mu 1$ serum-free Opti-MEMI medium (Invitrogen; Thermo Fisher Scientific, Inc.) and mixed gently at room temperature for $5 \mathrm{~min} ; 2 \mu \mathrm{g}$ Beclin-1 plasmid was added to $50 \mu \mathrm{l}$ serum-free Opti-MEMI medium and mixed gently. After $5 \mathrm{~min}$, the diluted Lipofectamine $2000^{\circledR}$ was gently mixed with the diluted Beclin-1 plasmid at room temperature for $20 \mathrm{~min}$. Subsequent to transfection with Beclin-1 or control plasmids (empty PCDNA3.0 vector), the 24 -well plate was incubated at $37^{\circ} \mathrm{C}$ with $5 \% \mathrm{CO}_{2}$ for $6 \mathrm{~h}$, following which the culture medium was replaced with complete medium.

Immunohistochemical staining. The paraffin sections were incubated at $65^{\circ} \mathrm{C}$ for $2 \mathrm{~h}$ and dewaxed in xylene for $20 \mathrm{~min}$ at room temperature. The specimens were washed with distilled water three times, incubated in $3 \% \mathrm{H}_{2} \mathrm{O}_{2}$ at room temperature for $10 \mathrm{~min}$ and washed with distilled water again. Antigen retrieval was performed using Tris-EDTA buffer (Sigma-Aldrich; Merck KGaA, Darmstadt, Germany) in a pressure cooker at medium to high pressure for $3 \mathrm{~min}$. Subsequent to washing with PBS, the specimens were incubated with monoclonal primary antibody against Beclin-1 (1:500; cat. no. ab210498; Abcam, Cambridge, UK) at $4^{\circ} \mathrm{C}$ overnight. The specimens were then rinsed with PBS buffer, and incubated in a 1:1,000 solution of biotin-labeled anti-Human Immunoglobulin G (IgG) secondary antibody (cat. no. SAB3701279; Sigma-Aldrich; Merck KGaA) at room temperature for $60 \mathrm{~min}$. The specimens were washed with PBS buffer and treated with 3,3-Diaminobenzidine (Sigma-Aldrich; Merck, KGaA) for $2 \mathrm{~min}$ at room temperature.
Slides were counterstained with hematoxylin for $1 \mathrm{~min}$ at room temperature, washed with distilled water, dehydrated sequentially with a graded ethanol series (80, 95 and 100\% ethanol), transparentized with xylene and sealed with neutral gum at room temperature.

Immunohistochemical staining analysis. For each section, 10 high-power fields at magnification, x400 were randomly selected, and $\sim 500$ cells were counted in each field. Scores between 0-3 were assigned according to staining intensity and the number of positive cells. The cells were scored as follows: No staining, 0; light yellow, 1; pale brown, 2; dark brown, 3. The number of positive cells was scored as follows: $<10 \%$, $0 ; 10-45 \%, 1 ; 45-70 \%, 2$; and $>70 \%, 3$. The two scores were totaled and the sum was divided into 4 levels: A total score of 1 was considered negative (-), a score of 2 as weakly positive (+), a score of 3-4 as positive (++), and a score of 5-6 as strongly positive $(+++)$. Negative and weakly positive were regarded as low expression, while positive and strongly positive as high expression.

Western blotting analysis. Tissues were lysed in buffer containing $50 \mathrm{mM}$ Tris ( $\mathrm{pH} 7.4), 150 \mathrm{mM} \mathrm{NaCl}, 1 \%$ nonidet P-40, $0.25 \%$ sodium deoxycholate, $1 \mathrm{mM}$ EDTA, $1 \mathrm{mM}$ phenylmethylsulfonyl fluoride and $1 \%$ protease cocktail inhibitor, followed by centrifugation at $12,000 \mathrm{x} \mathrm{g}$ for $10 \mathrm{~min}$ at $4^{\circ} \mathrm{C}$. The tissue lysis supernatants were collected and the protein concentrations were determined using BCA Protein Quantification kit (cat. no. 23227; Thermo Fisher Scientific, Inc.). A total of $20 \mu \mathrm{g}$ protein samples were loaded in each well and separated by electrophoresis in a $10 \%$ SDS-polyacrylamide gel and transferred to a polyvinylidene fluoride membrane (EMD Millipore, Billerica, MA, USA). Subsequent to blocking with $5 \%$ milk in TBS containing $0.1 \%$ Tween-20 (TBST) at room temperature for $2 \mathrm{~h}$, the membrane was incubated with primary antibodies against Beclin-1 (1:1,000; cat. no. ab210498; Abcam), light chain (LC) 3 II/I (1:500; cat. no. ab128025; Abcam), B-cell lymphoma-extra large (Bcl-xL; 1:800; cat. no. ab2568; Abcam) and $\beta$-actin (1:4,000; cat. no. A5441; Sigma-Aldrich; Thermo Fisher Scientific, Inc.). Following washing, membranes were incubated with a 1:3,000 solution of goat anti-rabbit IgG HRP-conjugated secondary antibody (cat. no. 7074; Cell Signaling Technology, Inc., Danvers, MA, USA) for $2 \mathrm{~h}$ at room temperature. The antigen-antibody complexes were detected using Western Lightening Plus enhanced chemiluminescence reagent (cat. no. NEL103E001EA; PerkinElmer, Inc., Waltham, MA, USA) with $\beta$-actin as the internal control protein. For immunoblotting quantification, the band intensity of the target protein was normalized to the internal control protein band from the same lane (ImageJ software, version 1.6; National Institutes of Health, Bethesda, MD, USA). Data were presented as the mean \pm standard deviation of $\geq 3$ replications for each group.

Apoptosis assay. At $48 \mathrm{~h}$ post-transfection, the cells were washed twice with cold PBS and dual staining was performed using the Annexin V-fluorescein isothiocyanate (FITC) Apoptosis Staining/Detection kit (cat. no. 55654; BD Biosciences, Franklin Lanes, NJ, USA). Briefly, cells were resuspended in $1 \mathrm{X}$ binding buffer at a concentration 
Table I. Expression of Beclin-1 in gastric carcinoma and para-carcinoma tissue samples.

\begin{tabular}{lccc}
\hline Group & Cases & $\begin{array}{c}\text { Low } \\
\text { expression }\end{array}$ & $\begin{array}{c}\text { High } \\
\text { expression }\end{array}$ \\
\hline Para-carcinoma tissue & 60 & 14 & 46 \\
Gastric carcinoma tissue & 60 & 38 & $22^{\mathrm{a}}$ \\
\hline
\end{tabular}

${ }^{\mathrm{a}} \mathrm{P}<0.01$.

of $1 \times 10^{6}$ cells $/ \mathrm{ml}$. The $100 \mu \mathrm{l}$ solution was transferred to a 5-ml culture tube. A total of $5 \mu \mathrm{l}$ Annexin V-FITC and $5 \mu \mathrm{l}$ propidium iodide were added to the tube and incubated for $15 \mathrm{~min}$ at $37^{\circ} \mathrm{C}$. A total of $400 \mu \mathrm{l} 1 \mathrm{X}$ binding buffer was added to each tube. The cells were evaluated by flow cytometer (BD Biosciences) and data were analyzed by FCS Express software (version 3; De Novo Software, Los Angeles, CA, USA).

Cell migration assay. Following transfection, the cells were collected and resuspended in serum-free DMEM at a concentration of $1 \times 10^{5}$ cells $/ \mathrm{ml}$. The lower chambers of Transwells (8 $\mu \mathrm{m}$ pore size; Corning Incorporated, Corning, NY, USA) were filled with $800 \mu \mathrm{l}$ DMEM with $10 \%$ FBS, and $400 \mu \mathrm{l}$ cell suspension was added to the upper chamber. Subsequent to incubation at $37^{\circ} \mathrm{C}$ with $5 \% \mathrm{CO}_{2}$ in air for $48 \mathrm{~h}$, cells on the lower surface were fixed with $75 \%$ ethanol for $30 \mathrm{~min}$ at room temperature and stained with $0.1 \%$ crystal violet for 2 min at room temperature. The migrated cells were counted at magnification, x60 using a light microscope (BX60; Olympus Corporation, Tokyo, Japan). Cells were counted in 3-5 fields of interest, which were randomly selected on each membrane, and the average number of cells was calculated.

Statistical analysis. Statistical analyses were performed using SPSS 19.0 software (IBM Corp., Armonk, NY, USA) and GraphPad Prism 5 (GraphPad Software, Inc., La Jolla, CA, USA). $\mathrm{P}<0.05$ was considered to indicate a statistically significant difference. The results were analyzed with $\chi^{2}$ tests.

\section{Results}

Detection of Beclin-1 protein expression in gastric tumor tissues. The immunohistochemical results demonstrated that positive Beclin-1 staining was primarily localized in the cytoplasm and occasionally in the nuclei (Fig. 1). Beclin-1 protein expression was positive in the majority of para-carcinoma tissue samples, with a positive expression rate of $76.67 \%$ (46/60). Gastric cancer tissues were primarily negative or weakly positive for Beclin-1, with a positive expression rate of $36.67 \%$ (22/60). The frequency of positive Beclin-1 expression in gastric carcinoma tissue samples was significantly lower compared with that in para-carcinoma samples $(\mathrm{P}<0.01$; Table I).

Detection of Beclin-1 protein expression in gastric carcinoma tissues by western blotting. Western blot analysis indicated that Beclin-1 protein expression in para-carcinoma tissue

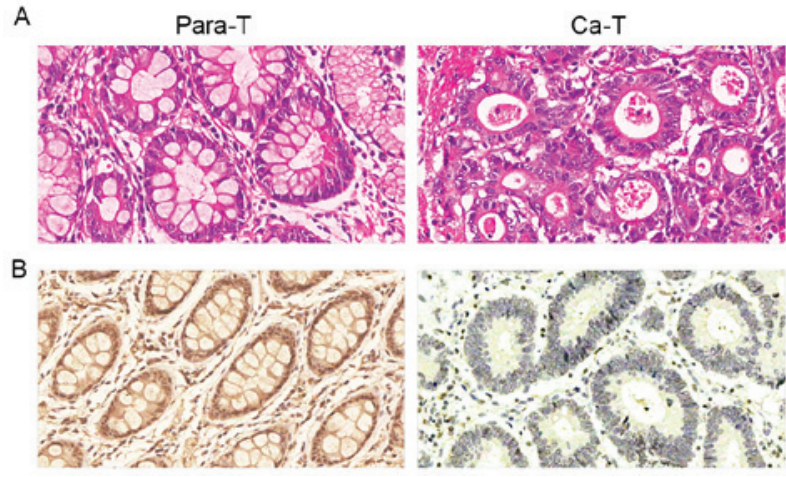

Figure 1. Expression of Beclin-1 in gastric Ca-T and Para-T samples (A) Representative images of hematoxylin and eosin staining in Para-T and Ca-T samples (magnification, x400). (B) Representative images of Beclin-1 immunohistochemical staining to demonstrate that Beclin-1 protein expression was highly positive in Para-T samples, whereas gastric carcinoma tissue was predominantly negative for Beclin-1 (magnification, x400). Para-T, para-carcinoma tissue; $\mathrm{Ca}-\mathrm{T}$, gastric carcinoma tissue.

A

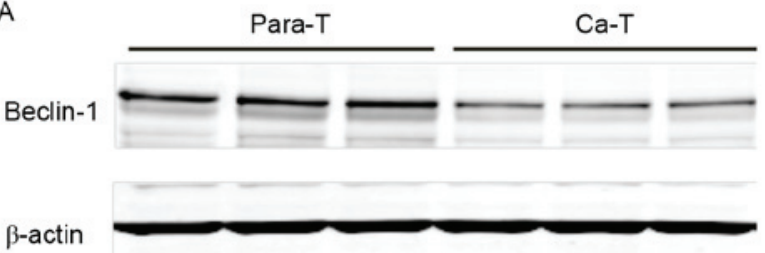

B

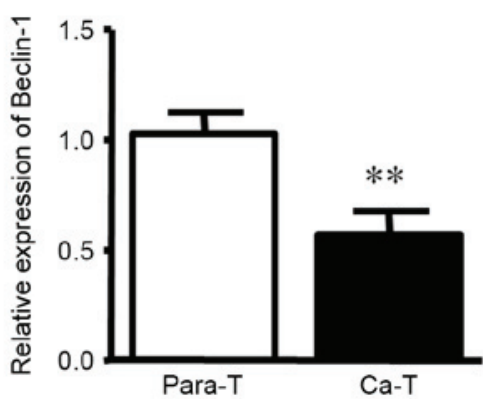

Figure 2. Expression of Beclin-1 protein in in Para-T and Ca-T samples as determined by western blotting. (A) Representative image of western blotting to demonstrate the expression level of Beclin-1 protein in in Para-T and Ca-T samples. (B) Quantification of the western blot analysis. ${ }^{* *} \mathrm{P}<0.01$. Para-T, para-carcinoma tissue; $\mathrm{Ca}-\mathrm{T}$, gastric carcinoma tissue.

samples was markedly higher than in tumor tissue (Fig. 2; $1.024 \pm 0.097$ vs. $0.572 \pm 0.102 ; \mathrm{P}<0.01)$.

Correlation between Beclin-1 protein expression and clinical characteristics. Based on the Beclin-1 protein expression levels detected by immunohistochemical staining, the gastric carcinoma specimens were divided into a low expression group $(-,+)$ and a high expression group $(++,+++)$. The clinical data of 60 cases were reviewed, and it was demonstrated that Beclin-1 protein expression was not associated with age, sex, tumor size, differentiation or lymph node metastasis, whereas it was associated with TNM stage $(\mathrm{P}=0.008)$ and invasion status (Table II; $\mathrm{P}=0.035$ ).

Gastric cancer cell line apoptosis and migration in Beclin-1 overexpression. As Beclin-1 expression was low in the gastric 
Table II. Association between Beclin-1 expression and clinical parameters in gastric carcinoma tissue samples.

\begin{tabular}{|c|c|c|c|c|c|}
\hline Clinical parameters & Cases & Low expression $(-,+)$ & High expression $(++,+++)$ & $\chi^{2}$ & P-value \\
\hline Age, years & & & & 1.279 & 0.258 \\
\hline$<60$ & 27 & 15 & 12 & & \\
\hline$\geq 60$ & 33 & 23 & 10 & & \\
\hline Sex & & & & 0.745 & 0.388 \\
\hline Male & 37 & 25 & 12 & & \\
\hline Female & 23 & 13 & 10 & & \\
\hline Tumor size, $\mathrm{cm}$ & & & & 0.191 & 0.662 \\
\hline$<5$ & 36 & 22 & 14 & & \\
\hline$\geq 5$ & 24 & 16 & 8 & & \\
\hline Differentiation & & & & 0.269 & 0.604 \\
\hline Low & 38 & 25 & 13 & & \\
\hline Moderate-high & 22 & 13 & 9 & & \\
\hline Tumor node metastasis stage & & & & 6.969 & $0.008^{\mathrm{a}}$ \\
\hline $\mathrm{I} / \mathrm{II}$ & 39 & 20 & 19 & & \\
\hline III/IV & 21 & 18 & 3 & & \\
\hline \multicolumn{6}{|l|}{ Lymph node metastasis } \\
\hline Negative & 36 & 26 & 10 & 3.060 & 0.080 \\
\hline Positive & 24 & 12 & 12 & & \\
\hline \multicolumn{6}{|l|}{ Invasion status } \\
\hline Mucosa and muscle & 42 & 23 & 19 & 4.429 & $0.035^{\mathrm{b}}$ \\
\hline Serosa & 18 & 15 & 3 & & \\
\hline
\end{tabular}

${ }^{\mathrm{a}} \mathrm{P}<0.01 ;{ }^{\mathrm{b}} \mathrm{P}<0.05$.

carcinoma tissues and correlated with the TNM stage and invasion status of patients, the present study aimed to characterize the role of Beclin-1 in gastric cancer. A previous study indicated that Beclin-1 expression was associated with tumor cell apoptosis and migration (6); therefore, we hypothesized that Beclin-1 acted through a similar mechanism in gastric cancer. Beclin-1-overexpressing gastric cancer cells were produced by the plasmid transfection of MKN-45 gastric cancer cells. As indicated in Fig. 3A, the apoptosis rate was increased in the overexpression group $(22.6 \pm 3.1 \%)$ compared with the control transfection group $(8.4 \pm 1.4 \%)$ at $48 \mathrm{~h}$ post-transfection. A significant difference in the apoptosis rate between the groups was observed (Fig. 3B; P<0.01).

A Transwell assay was employed to evaluate the effect of Beclin-1 on MKN-45 cell invasion. The numbers of migrating cells in the Beclin-1 overexpression and control groups were $28.4 \pm 5.1$ and $75.9 \pm 6.9$, respectively, which was demonstrated to be a statistically significant difference (Fig. 3C; $\mathrm{P}<0.01$ ).

To further explore the mechanisms for Beclin-1-regulated apoptosis resistance, alterations to the protein expression levels of the downstream autophagy effector LC 3 II/I and the pro-apoptotic factor Bcl-xL were examined by western blotting. Beclin-1 overexpression was associated with the increased expression of the autophagy effector LC 3 II/I and the reduced expression of the anti-apoptotic factor $\mathrm{Bcl}-\mathrm{xL}$ (Fig. 3D). The data indicated that Beclin-1 promoted autophagy and apoptosis.

\section{Discussion}

The present study explored whether tumor Beclin-1 expression was associated with the clinical features of patients with gastric cancer. Reduced Beclin-1 expression levels were identified in gastric carcinoma tumor tissue, suggesting that Beclin-1 expression may be associated with the occurrence and development of gastric cancer. However, the association between Beclin-1 expression and the clinicopathological characteristics of different tumors is complex, and under debate. A number of studies have demonstrated that the high expression of Beclin-1, as confirmed by immunohistochemistry, is correlated with unfavorable clinicopathological parameters $(3,16,17)$; however, other studies concluded that the pathogenesis and progression of cancer were associated with reduced Beclin-1 expression, which is consistent with the present study $(6,9,18)$. These data indicated that Beclin-1 may induce different effects in different types of tumors, depending on the intrinsic characteristics of the tumors themselves.

In the present study, Beclin-1 expression in gastric carcinoma tissue samples was negatively associated with TNM stage (Table II; $\mathrm{P}=0.008$ ), although the association between Beclin-1 expression and other clinical parameters of the patients, including tumor size, histological differentiation and metastatic status were not statistically significant. A previous study identified that Beclin-1 expression in stage 1 and 2 gastric cancer tissue samples was higher, whereas Beclin-1 expression levels in stage 3 gastric cancer tissue samples was 
A

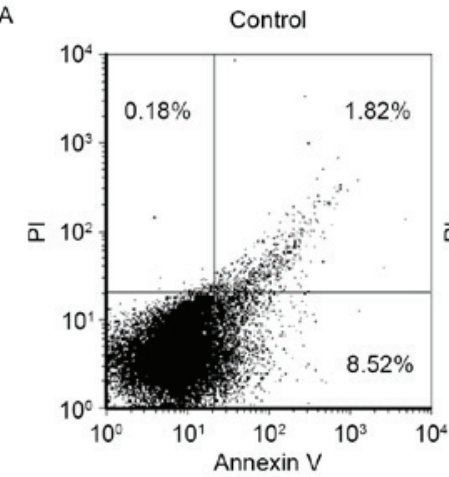

C

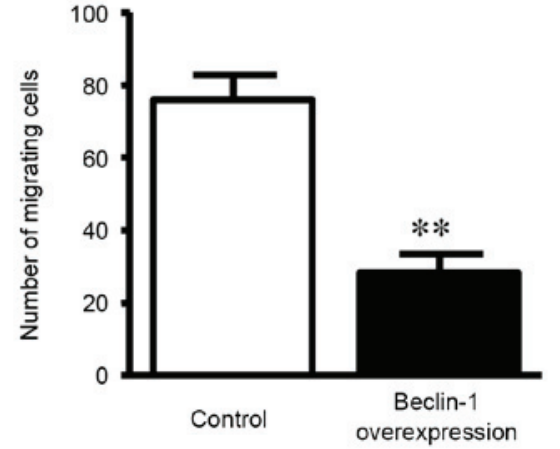

Beclin-1 overexpression

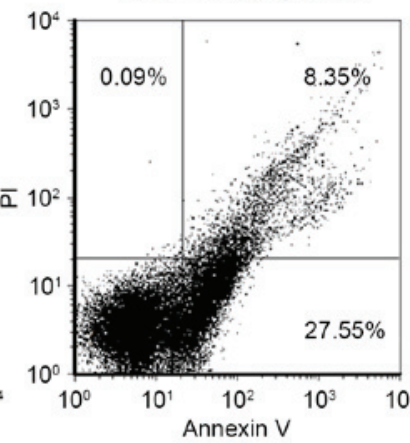

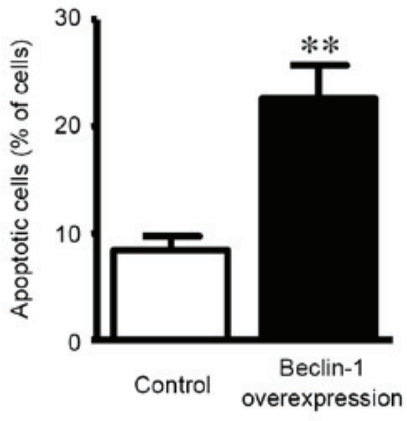

D

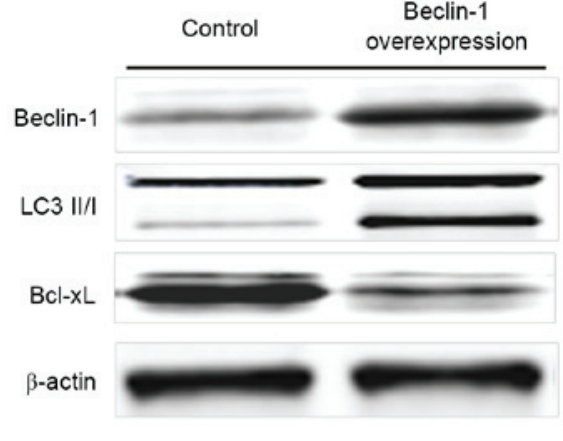

Figure 3. MKN-45 cell apoptosis and migration following Beclin-1 overexpression. (A) Apoptosis was promoted in the Beclin-1-overexpressing cells. A total of 3 independent experiments were performed and representative images are presented. (B) Statistical analysis of apoptosis in Beclin-1-overexpressing cells ${ }^{* *} \mathrm{P}<0.01$. (C) Cell migration was inhibited in the Beclin-1-overexpressing cells. Each experiment was repeated three times. ${ }^{* *} \mathrm{P}<0.01$. (D) Beclin-1 overexpression increased the expression levels of the autophagy effector LC 3 II/I, and reduced that of the anti-apoptotic factor Bcl-xL. Representative western blotting images are presented. Bcl-xL, B-cell lymphoma 2-extra large; PI, propidium iodide.

significantly lower, than in normal adjacent tissues (4). These data were consistent with the data of the present study, which revealed that Beclin-1 expression was associated with gastric carcinoma TNM stage, implying that the detection of high Beclin-1 expression levels in patients with gastric cancer may be an effective strategy for predicting the tumor invasion and stage phenotype.

Autophagy and apoptosis serve a central role in maintaining homeostasis and disease progression (19), two processes that are regulated by complex biological processes including interactions between the autophagy-associated protein Beclin-1 and the anti-apoptotic protein B-cell lymphoma 2 (Bcl-2) (20,21). Previous studies identified that Beclin-1 possesses a BH3 domain near its N-terminus, which may combine with the BH3 domains of apoptosis-associated proteins including Bcl-2 and Bcl-xL $(22,23)$. The binding of Bcl-2 family members to Beclin-1 may suppress the formation of the pro-autophagy Beclin-1/hVps34 complex formation and reduce Beclin-1-associated PI3 K activity, therefore inhibiting Beclin-1-induced autophagy (24). In addition, previous studies demonstrated that higher $\mathrm{Bcl}-2 / \mathrm{Bcl}-\mathrm{xL}$ expression levels were significantly correlated with lower Beclin-1 expression levels in liver and lung cancer, and other types of tumor tissue $(25,26)$.

However, other $\mathrm{BH} 3$-binding proteins, including Bcl-2-associated agonist of cell death, may also combine with the Beclin-1 BH3 domain, interrupting the interaction between Beclin-1 and Bcl-2/Bcl-xL, therefore increasing autophagy activity and inhibiting tumor growth $(24,27)$. The present study identified that the upregulation of Beclin-1 promoted apoptosis in gastric cancer cells. A potential mechanism is that Beclin-1 overexpression inhibited the expression of the anti-apoptotic factor Bcl-xL, triggering the apoptosis pathway. These results suggest that the mutual regulation of autophagy and apoptosis serve a pivotal role in gastric tumorigenesis.

A previous study demonstrated that Beclin-1 lentivirus transfection may inhibit cell migration in tongue squamous cell carcinoma cell (28). Vascular endothelial growth factor, and matrix metalloproteinase- 2 and -9 were identified as associated with the Beclin-1-mediated inhibition of migration and invasion (28). Another study suggested that increased Beclin-1 expression, as a tumor suppressor, contributed to the inhibition of tumor growth and metastasis in gastric adenocarcinoma through regulating the hedgehog signaling pathway (29). Therefore, it is reasonable to hypothesize that Beclin-1 interaction with other associated molecules regulated tumor cell migration. The data from the present study demonstrated that the overexpression of Beclin-1 may inhibit tumor cell migration, which also suggests that Beclin-1 expression is associated with tumor invasion in gastric cancer. Novel autophagy-based interventions, including $\mathrm{Bcl}-2$ family regulation, caspase-dependent cleavage of autophagy-related gene protein and microRNA mimics to downregulate Beclin-1 have already been clinically or experimentally applied, suggesting promising approaches for novel clinical treatments (30-32).

In summary, the present study investigated the association between Beclin-1 expression, clinically relevant parameters and gastric carcinoma progression. Beclin-1 was associated with the invasion status and TNM stage of gastric carcinoma tissue samples, two major factors affecting the prognosis of 
patients with gastric cancer. Increased apoptosis and reduced cell migration were observed in gastric cancer cells overexpressing Beclin-1, indicating a potential mechanism for the effect of Beclin-1 in suppressing gastric cancer progression.

\section{Acknowledgements}

The present study was supported by grants from the Natural Science Foundation of Shanghai Health and Family Planning Commission (grant no. 201540088) and the China National Natural Science Foundation of China (grant no. 81370961).

\section{References}

1. Chen $\mathrm{N}$ and Karantza-Wadsworth V: Role and regulation of autophagy in cancer. Biochim Biophys Acta 1793: 1516-1523, 2009.

2. Sakakura K, Takahashi H, Kaira K, Toyoda M, Oyama T and Chikamatsu K: Immunological significance of the accumulation of autophagy components in oral squamous cell carcinoma. Cancer Sci 106: 1-8, 2015.

3. Chen Y, Li X, Wu X, He C, Guo L, Zhang S, Xiao Y, Guo W and Tan B: Autophagy-related proteins LC 3 and Beclin-1 impact the efficacy of chemoradiation on esophageal squamous cell carcinoma. Pathol Res Pract 209: 562-567, 2013.

4. Fei B, Ji F, Chen X, Liu Z, Li S, Mo Z and Fang X: Expression and clinical significance of Beclin-1 in gastric cancer tissues of various clinical stages. Oncol Lett 11: 2271-2277, 2016.

5. Zhao Y, Chen S, Gou WF, Xiao LJ, Takano Y and Zheng HC: Aberrant Beclin 1 expression is closely linked to carcinogenesis differentiation, progression, and prognosis of ovarian epithelial carcinoma. Tumour Biol 35: 1955-1964, 2014.

6. Qiu DM, Wang GL, Chen L, Xu YY, He S, Cao XL, Qin J, Zhou JM, Zhang YX and E Q: The expression of beclin-1, an autophagic gene, in hepatocellular carcinoma associated with clinical pathological and prognostic significance. BMC Cancer 14: 327, 2014.

7. Miracco C, Cevenini G, Franchi A, Luzi P, Cosci E, Mourmouras V, Monciatti I, Mannucci S, Biagioli M and Toscano M: Beclin 1 and LC3 autophagic gene expression in cutaneous melanocytic lesions. Hum Pathol 41: 503-512, 2010.

8. Zaanan A, Park JM, Tougeron D, Huang S, Wu TT, Foster NR and Sinicrope FA: Association of beclin 1 expression with response to neoadjuvant chemoradiation therapy in patients with locally advanced rectal carcinoma. Int J Cancer 137: 1498-1502, 2015.

9. Wang Y, Wang C, Tang H, Wang M, Weng J, Liu X, Zhang R, Huang $\mathrm{H}$ and Hou J: Decrease of autophagy activity promotes malignant progression of tongue squamous cell carcinoma J Oral Pathol Med 42: 557-564, 2013.

10. Liang XH, Jackson S, Seaman M, Brown K, Kempkes B, Hibshoosh $\mathrm{H}$ and Levine B: Induction of autophagy and inhibition of tumorigenesis by beclin 1. Nature 402: 672-676, 1999.

11. Lozy F and Karantza V: Autophagy and cancer cell metabolism. Semin Cell Dev Biol 23: 395-401, 2012.

12. Kongara S, Kravchuk O, Teplova I, Lozy F, Schulte J, Moore D, Barnard N, Neumann CA, White E and Karantza V: Autophagy regulates keratin 8 homeostasis in mammary epithelial cells and in breast tumors. Mol Cancer Res 8: 873-884, 2010.

13. Gallagher LE, Williamson LE and Chan EY: Advances in autophagy regulatory mechanisms. Cells 5: pii: E24, 2016.

14. Ozpolat B and Benbrook DM: Targeting autophagy in cancer management-strategies and developments. Cancer Manag Res 7: 291-299, 2015.
15. Washington K: 7th edition of the AJCC cancer staging manual Stomach. Ann Surg Oncol 17: 3077-3079, 2010.

16. Guo GF, Jiang WQ, Zhang B, Cai YC, Xu RH, Chen XX, Wang F and Xia LP: Autophagy-related proteins Beclin-1 and LC3 predict cetuximab efficacy in advanced colorectal cancer. World J Gastroenterol 17: 4779-4786, 2011

17. Tang JY, Hsi E, Huang YC, Hsu NC, Chu PY and Chai CY: High LC3 expression correlates with poor survival in patients with oral squamous cell carcinoma. Hum Pathol 44: 2558-2562, 2013.

18. Burada F, Nicoli ER, Ciurea ME, Uscatu DC, Ioana M and Gheonea DI: Autophagy in colorectal cancer: An important switch from physiology to pathology. World J Gastrointest Oncol 7: 271-284, 2015

19. Nikoletopoulou V, Markaki M, Palikaras K and Tavernarakis N: Crosstalk between apoptosis, necrosis and autophagy. Biochim Biophys Acta 1833: 3448-3459, 2013.

20. Yue Z, Jin S, Yang C, Levine AJ and Heintz N: Beclin 1, an autophagy gene essential for early embryonic development, is a haploinsufficient tumor suppressor. Proc Natl Acad Sci USA 100: 15077-15082, 2003.

21. Zhao GX, Pan H, Ouyang DY and He XH: The critical molecular interconnections in regulating apoptosis and autophagy. Ann Med 47: 305-315, 2015.

22. Pattingre S, Tassa A, Qu X, Garuti R, Liang XH, Mizushima N, Packer M, Schneider MD and Levine B: Bcl-2 antiapoptotic proteins inhibit Beclin 1-dependent autophagy. Cell 122: 927-939, 2005.

23. Maiuri MC, Le Toumelin G, Criollo A, Rain JC, Gautier F, Juin P, Tasdemir E, Pierron G, Troulinaki K, Tavernarakis N, et al: Functional and physical interaction between $\mathrm{Bcl}-\mathrm{X}(\mathrm{L})$ and a BH3-like domain in Beclin-1. EMBO J 26: 2527-2539, 2007.

24. Levine B, Sinha SC and Kroemer G: Bcl-2 family members: Dual regulators of apoptosis and autophagy. Autophagy 4: 600-606, 2008.

25. Luo S and Rubinsztein DC: Apoptosis blocks Beclin 1-dependent autophagosome synthesis: An effect rescued by Bcl-xL. Cell Death Differ 17: 268-277, 2010.

26. Kang R, Zeh HJ, Lotze MT and Tang D: The Beclin 1 network regulates autophagy and apoptosis. Cell Death Differ 18: 571-580, 2011.

27. Lian J, Wu X, He F, Karnak D, Tang W, Meng Y, Xiang D, Ji M, Lawrence TS and Xu L: A natural BH3 mimetic induces autophagy in apoptosis-resistant prostate cancer via modulating Bcl-2-Beclin1 interaction at endoplasmic reticulum. Cell Death Differ 18: 60-71, 2011.

28. Weng J, Wang C, Wang Y, Tang H, Liang J, Liu X, Huang H and Hou J: Beclin1 inhibits proliferation, migration and invasion in tongue squamous cell carcinoma cell lines. Oral Oncol 50: 983-990, 2014

29. Won KY, Kim GY, Lim SJ, Sung JY, Kim YW, Park YK, Lee J and Choi HS: Autophagy is related to the hedgehog signaling pathway in human gastric adenocarcinoma: Prognostic significance of Beclin-1 and Gli2 expression in human gastric adenocarcinoma. Pathol Res Pract 211: 308-315, 2015.

30. Mathew R, Kongara S, Beaudoin B, Karp CM, Bray K, Degenhardt K, Chen G, Jin S and White E: Autophagy suppresses tumor progression by limiting chromosomal instability. Genes Dev 21: 1367-1381, 2007

31. Hasima N and Ozpolat B: Regulation of autophagy by polyphenolic compounds as a potential therapeutic strategy for cancer. Cell Death Dis 5: e1509, 2014.

32. Geng Z, Xu F and Zhang Y: MiR-129-5p-mediated Beclin-1 suppression inhibits endothelial cell autophagy in atherosclerosis. Am J Transl Res 8: 1886-1894, 2016. 